\title{
Colour and dyeing properties of hetarylazo disperse dyes: Visual and instrumental evaluation
}

\author{
Georgiadou Kyriaki, Eleftheriadis Ioannis", Tsatsaroni Eforia \\ Department of Chemistry, Aristotle University of Thessaloniki, 54124 Thessaloniki, Greece
}

Email address:

elefther@chem.auth.gr (E. Ioannis)

\section{To cite this article:}

Georgiadou Kyriaki, Eleftheriadis Ioannis, Tsatsaroni Eforia. Colour and Dyeing Properties of Hetarylazo Disperse Dyes: Visual and Instrumental Evaluation. American Journal of Applied Chemistry. Vol. 2, No. 2, 2014, pp. 33-37. doi: 10.11648/j.ajac.20140202.12

\begin{abstract}
The colour and dyeing properties temperature range and rate of dyeing of 14 hetarylazo disperse dyes previously synthesized and applied by exhaustion on cellulose acetate were evaluated visually and instrumentally and the results were compared and reported. A satisfactory agreement between the visual and the instrumental evaluation of these properties was concluded.
\end{abstract}

Keywords: Disperse Dyes, Cellulose Acetate, Temperature Range, Rate of Dyeing

\section{Introduction}

In recent years, efforts have been made to replace certain anthraquinone dyes with technically equivalent azo dyes, for both environmental and economic reasons [1]. In this regard, azo dyes based on heterocyclic amines have been developed and the resultant dyes have higher tinctorial strength and give brighter dyeings than those derived from aniline-based diazo components. For instance aminosubstituted thiazole or isothiazole compounds contain very electronegative diazo components and, consequently, provide a pronounced bathochromic effect as compared to the corresponding benzenoid compounds [2-4]. It is well known that ring systems of this type are useful for providing blue and green azo dyes which can not be achieved using aniline-based compounds as diazo components

In continuation of our previous work on the synthesis, characterization and application of hetarylazo disperse dyes [5-7] we report here a simple way of visual assessment of the dyeing properties: rate of dyeing and temperature range of those dyes. It is well known, that the high precision measurement of colour requires the use of colorimeters, reflectance spectrophotometers or recently of video cameras [8].

The dyes studied were derived from the diazotized heterocyclic amines 6-methoxy-2-amino-benzothiazole 1, 6-nitro-2-amino-benzothiazole 2 and 3-amino-5nitro[2,1]benzoisothiazole 3 after coupling with the amines $\mathrm{N}$-methyl-N- $\beta$-methoxycarbonyl-ethylaniline a, 3-
acetylamino-N,N-bis- $\beta$-methoxycarbonyl-ethylaniline b, 3acetylamino-N,N-bis- $\beta$-hydroxy-ethylaniline c, 2-methoxy5 -acetylamino-N,N- $\beta$-acetoxyethylaniline $\mathrm{d}$ and $\mathrm{N}-\beta$ hydroxyethyl-1-naphtylamine e [5-7] ( Figure 1).
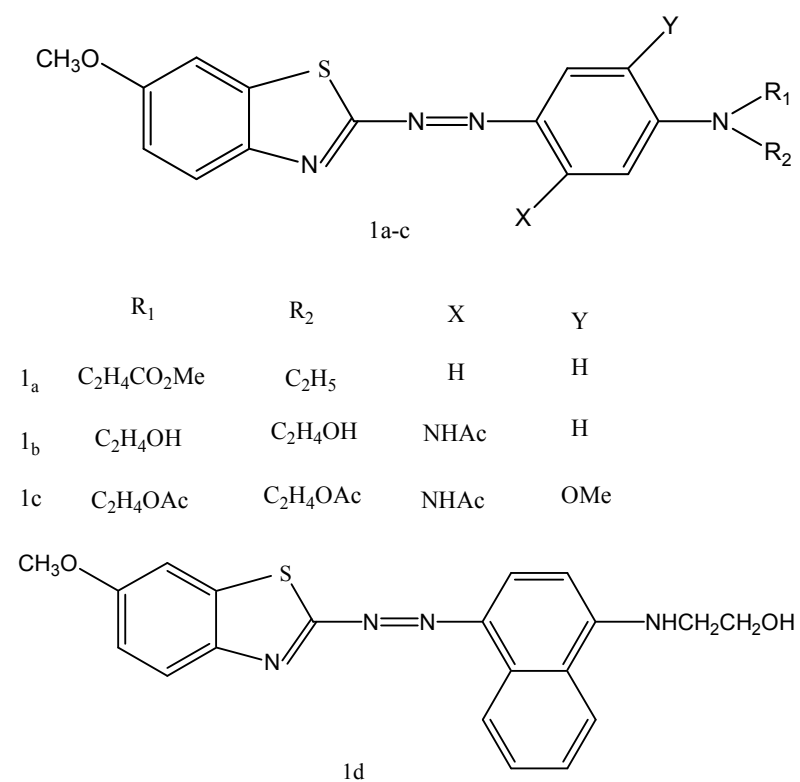

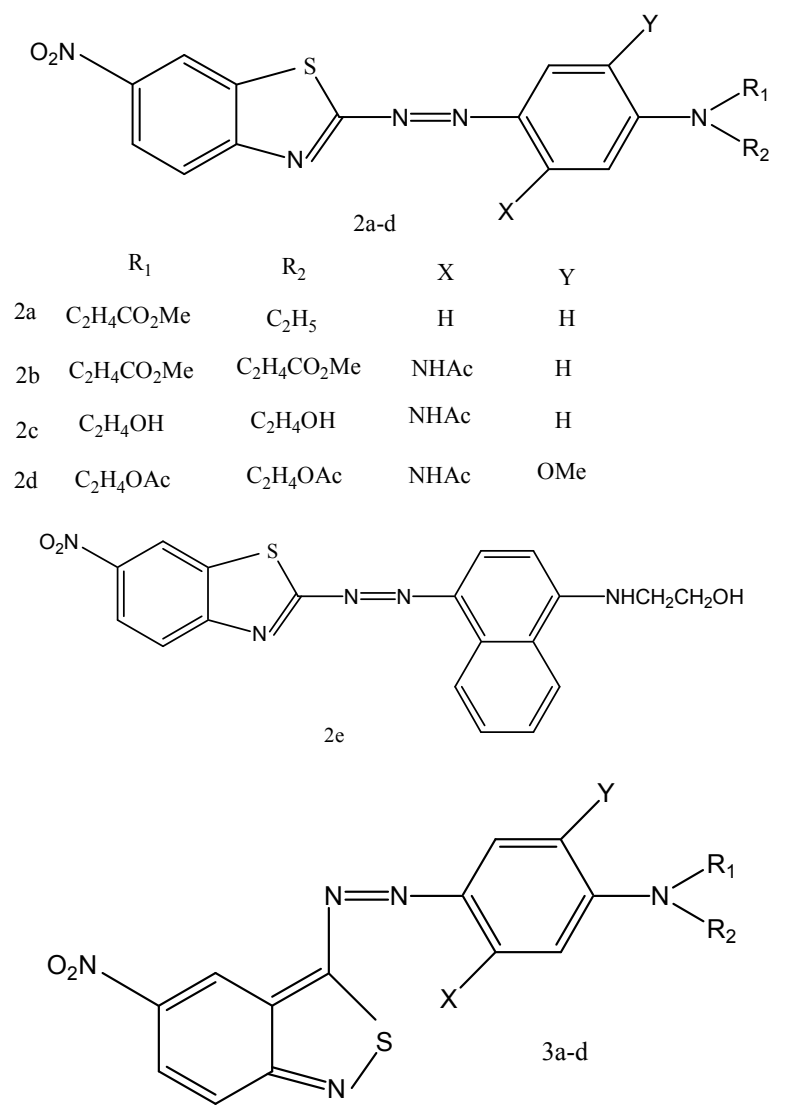

$$
\begin{array}{ccccc} 
& \multicolumn{1}{c}{\mathrm{R}_{1}} & \mathrm{R}_{2} & \mathrm{X} & \mathrm{Y} \\
\text { 3a } & \mathrm{C}_{2} \mathrm{H}_{4} \mathrm{CO}_{2} \mathrm{Me} & \mathrm{C}_{2} \mathrm{H}_{5} & \mathrm{H} & \mathrm{H} \\
3 \mathrm{~b} & \mathrm{C}_{2} \mathrm{H}_{4} \mathrm{CO}_{2} \mathrm{Me} & \mathrm{C}_{2} \mathrm{H}_{4} \mathrm{CO}_{2} \mathrm{Me} & \mathrm{NHAc} & \mathrm{H} \\
3 \mathrm{c} & \mathrm{C}_{2} \mathrm{H}_{4} \mathrm{OH} & \mathrm{C}_{2} \mathrm{H}_{4} \mathrm{OH} & \text { NHAc } & \mathrm{H} \\
\text { 3d } & \mathrm{C}_{2} \mathrm{H}_{4} \mathrm{OAc} & \mathrm{C}_{2} \mathrm{H}_{4} \mathrm{OAc} & \text { NHAc } & \text { OMe }
\end{array}
$$

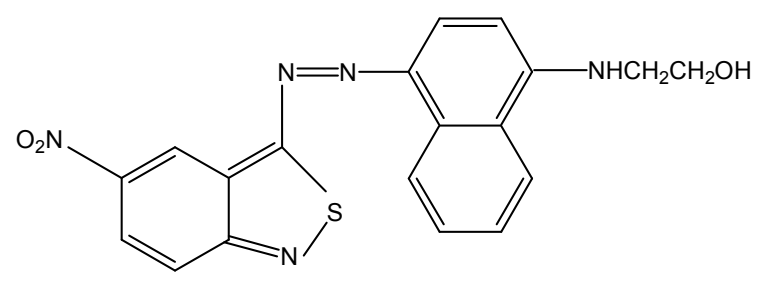

$3 \mathrm{e}$

Figure 1. Structure of the azo dyes studied

Their cellulose acetate dyeings were used for the visual assessment and the instrumental evaluation of their dyeing properties temperature range and rate of dyeing. The relation between the hues of the dyeings $\left(h^{\circ}\right)$ values and the absorption maxima ( $\lambda \max )$ of the methanol solutions of the dyes was also studied.

\section{Experimental}

\subsection{Materials, Methods and Apparatus}

Dyed samples at depth of dyeing $0.25,0.5$ and $1 \%$ o.w.f. were used in the study.
UV-visible spectra were recorded with a Shimadzu UV 2101 spectrophotometer using methanol as a solvent.

\subsubsection{Colour Measurement of the Dyed Fabrics}

Colour measurements were performed by winding the dyed fabric three times to give a sample size $\sim 3 \times 3 \mathrm{~cm}$. A total of four measurements were made of each sample from which the average was calculated.

A Macbeth CE 3000 Coloreye spectrophotometer interfaced to a P.C. (software Matchprobe 200), under illuminant $\mathrm{D}_{65}$ using a $10^{\circ}$ standard observer with specular and UV component included was used to measure the reflectance of the dyed fabrics. The corresponding $\mathrm{K} / \mathrm{S}$ values and CIE $L^{*}, a^{*}, b^{*}, C^{*}$ and $h^{\circ}$ values were calculated from the reflectance data at the appropriate $\lambda_{\max }$.

\subsubsection{Rate of Dyeing and Temperature Range Tests [9]}

These experiments were carried out at a target depth shade of $0.5 \%$ on the weight of the fibre (owf). In the first set of experiments dyeing was conducted at $85 \mathrm{oC}$ for 5,10 , 20, 80 and $160 \mathrm{~min}$. The resultant data were analysed by comparing results of dyeing after 5, 10, 20 and 80 min with the results after $160 \mathrm{~min}$ [9a]. In the second set of experiments dyeing was carried out at 50, 60, 70, 80 and $90^{\circ} \mathrm{C}$ for $1 \mathrm{~h}$. Results from the dyeing at $90^{\circ} \mathrm{C}$ was compared with those from dyeings at the lower temperatures [9b].

\section{Results and Discussion}

\subsection{Colour of dyes 1-3}

Synthesis and characterization of dyes 1-3 is reported in previous papers [5-7]. The dyes were applied to cellulose acetate and quality control (wash and light fastness properties) of the cellulose acetate dyeings was also reported [5-7]. The $\lambda_{\max }, \varepsilon_{\max }$ of the dye methanol solutions of the cellulose acetate samples dyed with a depth of shade $0.5 \%$ on the weight of the fabric (o.w.f.) are given in Table 1.

Table 1. $\lambda_{\max }$, molecular extinction coefficients $\varepsilon_{\max }$ and colour of the azodyes 1-3 solutions in methanol

\begin{tabular}{lllll}
\hline Dye & $\begin{array}{l}\boldsymbol{\lambda}_{\max }(\mathbf{n m}, \\
\left.\mathbf{C H}_{\mathbf{3}} \mathbf{O H}\right)\end{array}$ & $\begin{array}{l}\boldsymbol{\varepsilon}_{\mathbf{m a x}}\left(\mathbf{l} \cdot \mathbf{m o l}^{-1} \cdot \mathbf{c m}^{-1},\right. \\
\left.\mathbf{C H}_{\mathbf{3}} \mathbf{O H}\right)\end{array}$ & $\mathbf{l o g} \boldsymbol{\varepsilon}_{\max }$ & Colour \\
\hline 1a & 510.5 & 54945 & 4.74 & Red \\
1b & 529.0 & 58471 & 4.76 & Ruby red \\
1c & 544.5 & 38910 & 4.59 & Deepmagenta \\
1d & 561.0 & 54054 & 4.73 & Magenta \\
2a & 591.5 & 80645 & 4.91 & Violet \\
2b & 545.5 & 41667 & 4.62 & Violet \\
2c & 554.5 & 60241 & 4.78 & Violet \\
2d & 591.5 & 35714 & 4.55 & Blue \\
2e & 597.0 & 43860 & 4.64 & Dark blue \\
3a & 586.5 & 46948 & 4.67 & Dark blue \\
3b & 594.5 & 29499 & 4.47 & Dark blue \\
3c & 603.5 & 52083 & 4.72 & Deep blue \\
3d & 623.5 & 22831 & 4.36 & Dark blue \\
3e & 652.0 & 27701 & 4.44 & Deep blue \\
\hline
\end{tabular}


In Table 2 the colorimetric coordinates $\mathrm{L}^{*}, \mathrm{a}^{*}, \mathrm{~b}^{*}, \mathrm{C}^{*}, \mathrm{~h}^{\circ}$ and the $\mathrm{K} / \mathrm{S}$ values of the dyed samples with the dyes $1-3$ at standard depth $0.5 \%$ o.w.f. are given.

Table 2. Colorimetric coordinates $L^{*}, a^{*}, b^{*}, C^{*}, h^{\circ}$ and $K / S$ of the dyed samples with the dyes 1-3 at standard depth $0.5 \%$ o.w.f.

\begin{tabular}{crrrrrr}
\hline Dye & $\mathbf{L}^{*}$ & $\boldsymbol{\alpha}^{*}$ & $\mathbf{b}^{*}$ & $\mathbf{C}^{*}$ & \multicolumn{1}{c}{$\mathbf{h}^{\circ}$} & $\mathbf{K} / \mathbf{S}$ \\
\hline 1a & 35.19 & 55.63 & 21.02 & 59.46 & 20.70 & 29.88 \\
1b & 28.75 & 49.45 & -8.14 & 50.11 & 350.65 & 27.77 \\
1c & 22.82 & 33.63 & -17.73 & 38.02 & 332.20 & 27.07 \\
1d & 37.07 & 29.62 & -34.20 & 45.24 & 310.90 & 8.88 \\
2a & 24.48 & 39.45 & -20.37 & 44.40 & 332.69 & 25.52 \\
2b & 34.78 & 39.38 & -25.87 & 47.12 & 326.69 & 12.55 \\
2c & 33.14 & 36.92 & -22.89 & 43.44 & 328.20 & 13.12 \\
2d & 44.63 & 7.14 & -13.17 & 14.98 & 298.48 & 4.82 \\
2e & 31.57 & -1.38 & -6.24 & 6.39 & 257.49 & 9.05 \\
3a & 31.86 & 3.41 & -36.10 & 36.26 & 275.39 & 16.65 \\
3b & 36.71 & -6.86 & -27.73 & 28.57 & 256.10 & 11.34 \\
3c & 33.90 & -8.73 & -25.19 & 26.66 & 250.89 & 14.19 \\
3d & 44.38 & -2.48 & -11.23 & 11.50 & 257.56 & 3.40 \\
3e & 42.21 & -15.01 & -20.97 & 25.79 & 234.40 & 11.36 \\
\hline
\end{tabular}

As it was expected $[3,4,7,10,11]$ dyes $1(\mathrm{a}-\mathrm{d})-3(\mathrm{a}-\mathrm{e})$ derived from the heterocyclic diazo compounds benzothiazole and benzoisothiazole derivatives, i.e heterocyclic systems containing sulphur as the $\pi$-excessive heteroatom representing a very electronegative diazo component, have a marked bathochromic effect compared with the corresponding benzenoid compounds probably due to the greater stabilization of the excited state.

In Figure 2 the colour circle with the dyes 1-3 placed according to the $h^{0}$ value of the corresponding cellulose acetate dyeings is given.

From tables 1, 2 and figure 2 it is concluded that there is a general agreement between the hues of the dyeings $\left(\mathrm{h}^{\circ}\right)$, the subjective evaluation of the shades of the dyes on cellulose acetate and the absorption maxima of the dyes in methanol solution.

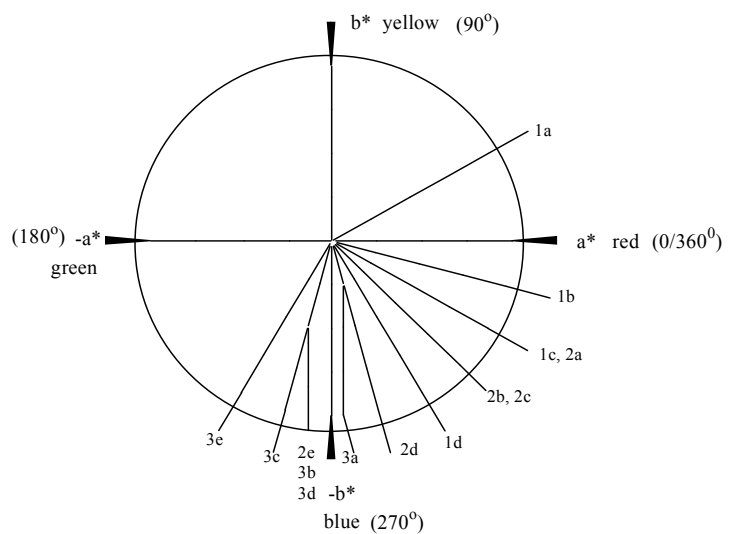

Figure 2. Colour circle with the dyes 1(a-d). 2(a-e), 3(a-e) marked on it.

The colorants gave dyeings of bright reddish to greenish - blue shades. It is evident that dye $1 \mathrm{~d}$ had the lowest lightness ( $\mathrm{L}^{*}$ value). This is attributed to the high adsorption of the dye (high $\mathrm{K} / \mathrm{S}$ ), while dye $2 \mathrm{~d}$ had the highest lightness explained by the low adsorption of that dye (low K/S).

\subsection{Dyeing Behavior of Dyes 1-3 (Rate of Dyeing, Temperature Range)}

Additionally to the wash and light fastness properties ofthe cellulose acetate dyeings already reported [5-7] the dyeing properties temperature range and rate of dyeing were measured spectrophotomatrically and evaluated visually in this study.

\subsubsection{Qualitative Assessment}

The dyeing behavior of dyes 1-3 was evaluated with respect to their dyeing rates and the effect of temperature on dye uptake (Tables 3-5)

Table 3: Instrumental and visual evaluation of the rate of dyeing and the temperature range tests of dyed acetate samples with the dyes 1 in the dyeing at depth of dyeing $0.5 \%$ owf

\begin{tabular}{|c|c|c|c|c|c|c|c|c|c|c|}
\hline \multirow[b]{2}{*}{ Dye } & \multicolumn{5}{|c|}{ Rate of dyeing test } & \multicolumn{5}{|c|}{ Temperature range test } \\
\hline & $\begin{array}{l}\text { Time of } \\
\text { dyeing (min) }\end{array}$ & $\Delta \mathbf{E}^{*} \boldsymbol{\alpha}$ & $\begin{array}{l}\text { Grey } \\
\text { scale }\end{array}$ & $\begin{array}{l}\text { Colour evaluation } \\
\text { instrument. }\end{array}$ & visual & $\begin{array}{l}\text { Temperature } \\
\text { of dyeing }\left({ }^{\circ} \mathrm{C}\right)\end{array}$ & $\Delta \mathbf{E}^{*} \boldsymbol{\beta}$ & $\begin{array}{l}\text { Grey } \\
\text { scale }\end{array}$ & $\begin{array}{l}\text { Colour evalua } \\
\text { instrument. }\end{array}$ & $\begin{array}{l}\text { tion } \\
\text { visual }\end{array}$ \\
\hline \multirow{4}{*}{$1 \alpha$} & 5 & 7.12 & 2 & & & 50 & 12.34 & $1-2$ & & \\
\hline & 10 & 2.45 & 4 & & & 60 & 4.87 & 3 & & \\
\hline & 20 & 2.16 & 4 & & & 70 & 1.75 & 4 & & \\
\hline & 80 & 1.24 & $4-5$ & $\mathrm{D}$ & $\mathrm{D}$ & 80 & 0.59 & $4-5$ & $\mathrm{D}$ & $\mathrm{D}$ \\
\hline \multirow{4}{*}{$1 \mathrm{c}$} & 5 & 13.87 & 1 & & & 50 & 22.05 & 1 & & \\
\hline & 10 & 7.47 & 2 & & & 60 & 12.00 & 1 & & \\
\hline & 20 & 3.60 & 3 & & & 70 & 6.98 & 2 & & \\
\hline & 80 & 0.97 & $4-5$ & D & D & 80 & 1.07 & $4-5$ & D & D \\
\hline \multirow{4}{*}{$1 d$} & 5 & 18.12 & 1 & & & 50 & 29.06 & 1 & & \\
\hline & 10 & 10.80 & $1-2$ & & & 60 & 19.83 & 1 & & \\
\hline & 20 & 3.76 & 3 & & & 70 & 10.67 & $1-2$ & & \\
\hline & 80 & 0.51 & $4-5$ & D & $\mathrm{D}$ & 80 & 2.74 & $3-4$ & E & $\mathrm{E}$ \\
\hline \multirow{4}{*}{ 1e } & 5 & 21.82 & 1 & & & 50 & 35.38 & 1 & & \\
\hline & 10 & 9.70 & $1-2$ & & & 60 & 22.23 & 1 & & \\
\hline & 20 & 5.97 & $2-3$ & & & 70 & 9.27 & 2 & & \\
\hline & 80 & 1.46 & 4 & E & $\mathrm{E}$ & 80 & 5.23 & $2-3$ & E & E \\
\hline
\end{tabular}

$\Delta \mathbf{E}^{* \alpha}$ : Colour difference of the dyed acetate sample at time of dyeing 160 min versus the corresponding dyed sample dyeing time $5,10,20 \mathrm{\kappa} \alpha \mathbf{1} 80 \mathrm{~min}$.

$\Delta \mathbf{E}^{* \beta}$ : Colour difference of the dyed acetate sample in dyeing temperature min versus the corresponding dyed sample in temperature $90^{\circ} \mathrm{C} 50,60,70$ and $80^{\circ} \mathrm{C}$. 
Table 4. Instrumental and visual evaluation of the rate of dyeing and the temperature range tests of dyed acetate samples with the dyes 2 in the dyeing at depth of dyeing $0.5 \%$ owf

\begin{tabular}{|c|c|c|c|c|c|c|c|c|c|c|}
\hline \multirow[b]{2}{*}{ Dye } & \multicolumn{5}{|c|}{ Rate of dyeing test } & \multicolumn{5}{|c|}{ Temperature range test } \\
\hline & $\begin{array}{l}\text { Time of dyeing } \\
\text { (min) }\end{array}$ & $\Delta \mathbf{E}^{*} \boldsymbol{\alpha}$ & $\begin{array}{l}\text { Grey } \\
\text { scale }\end{array}$ & $\begin{array}{l}\text { Colour evaluation } \\
\text { instrument. }\end{array}$ & visual & $\begin{array}{l}\text { Temperature of } \\
\text { dyeing }\left({ }^{\circ} \mathrm{C}\right)\end{array}$ & $\Delta E * \boldsymbol{B}$ & $\begin{array}{l}\text { Grey } \\
\text { scale }\end{array}$ & $\begin{array}{l}\text { Colour evaluatior } \\
\text { Instrument. }\end{array}$ & nisual \\
\hline \multirow{4}{*}{$2 \alpha$} & 5 & 19.99 & 1 & & & 50 & 25.64 & 1 & & \\
\hline & 10 & 10.16 & $1-2$ & & & 60 & 18.69 & 1 & & \\
\hline & 20 & 7.50 & 2 & & & 70 & 10.98 & $1-2$ & & \\
\hline & 80 & 2.84 & $3-4$ & E & E & 80 & 5.27 & $2-3$ & E & E \\
\hline \multirow{4}{*}{$2 b$} & 5 & 19.88 & 1 & & & 50 & 34.07 & 1 & & \\
\hline & 10 & 11.65 & $1-2$ & & & 60 & 19.79 & 1 & & \\
\hline & 20 & 6.50 & 2 & & & 70 & 8.85 & 2 & & \\
\hline & 80 & 1.89 & 4 & E & $\mathrm{E}$ & 80 & 1.82 & 4 & E & E \\
\hline \multirow{4}{*}{$2 \mathrm{c}$} & 5 & 14.70 & 1 & & & 50 & 20.44 & 1 & & \\
\hline & 10 & 9.36 & $1-2$ & & & 60 & 16.05 & 1 & & \\
\hline & 20 & 6.80 & 2 & & & 70 & 9.49 & $1-2$ & & \\
\hline & 80 & 1.50 & 4 & E & E & 80 & 5.07 & $2-3$ & E & E \\
\hline \multirow{4}{*}{$2 d$} & 5 & 17.57 & 1 & & & 50 & 24.34 & 1 & & \\
\hline & 10 & 11.72 & 1 & & & 60 & 17.18 & 1 & & \\
\hline & 20 & 7.99 & 2 & & & 70 & 12.40 & 1 & & \\
\hline & 80 & 1.69 & 4 & E & E & 80 & 6.71 & 2 & E & E \\
\hline \multirow{4}{*}{$2 e$} & 5 & 20.94 & 1 & & & 50 & 21.16 & 1 & & \\
\hline & 10 & 12.14 & 1 & & & 60 & 12.48 & 1 & & \\
\hline & 20 & 2.91 & $3-4$ & & & 70 & 5.69 & $2-3$ & & \\
\hline & 80 & 2.30 & $3-4$ & E & E & 80 & 3.36 & 3 & E & E \\
\hline
\end{tabular}

Table 5. Instrumental and visual evaluation of the rate of dyeing and the temperature range tests of dyed acetate samples with the dyes 3 in the dyeing at depth of dyeing $0.5 \%$ owf

\begin{tabular}{|c|c|c|c|c|c|c|c|c|c|c|}
\hline \multirow[b]{2}{*}{ Dye } & \multicolumn{5}{|c|}{ Rate of dyeing test } & \multicolumn{5}{|c|}{ Temperature range test } \\
\hline & $\begin{array}{l}\text { Time of dyeing } \\
\text { (min) }\end{array}$ & $\Delta \mathbf{E}^{*} \boldsymbol{\alpha}$ & $\begin{array}{l}\text { Grey } \\
\text { scale }\end{array}$ & $\begin{array}{l}\text { Colour evalu } \\
\text { instrument. }\end{array}$ & visual & $\begin{array}{l}\text { Temperature } \\
\text { of dyeing }\left({ }^{\circ} \mathrm{C}\right)\end{array}$ & $\Delta \mathbf{E}^{*} \boldsymbol{\beta}$ & $\begin{array}{l}\text { Grey } \\
\text { scale }\end{array}$ & $\begin{array}{l}\text { Colour eval } \\
\text { instrument }\end{array}$ & visual \\
\hline \multirow{4}{*}{$3 \alpha$} & 5 & 21.95 & 1 & & & 50 & 31.31 & 1 & & \\
\hline & 10 & 12.14 & 1 & & & 60 & 20.82 & 1 & & \\
\hline & 20 & 2.28 & 4 & & & 70 & 6.44 & 2 & & \\
\hline & 80 & 0.77 & 5 & $\mathrm{D}$ & $\mathrm{D}$ & 80 & 0.78 & $4-5$ & $\mathrm{D}$ & $\mathrm{D}$ \\
\hline \multirow{4}{*}{$3 b$} & 5 & 19.40 & 1 & & & 50 & 27.87 & 1 & & \\
\hline & 10 & 11.75 & $1-2$ & & & 60 & 21.58 & 1 & & \\
\hline & 20 & 9.08 & $1-2$ & & & 70 & 13.92 & 1 & & \\
\hline & 80 & 2.72 & $3-4$ & $\mathrm{E}$ & $\mathrm{E}$ & 80 & 6.66 & 2 & $\mathrm{E}$ & $\mathrm{E}$ \\
\hline \multirow{4}{*}{$3 \mathrm{c}$} & 5 & 23.20 & 1 & & & 50 & 36.49 & 1 & & \\
\hline & 10 & 16.82 & 1 & & & 60 & 27.01 & 1 & & \\
\hline & 20 & 10.89 & $1-2$ & & & 70 & 17.81 & 1 & & \\
\hline & 80 & 3.52 & 3 & E & E & 80 & 8.73 & $1-2$ & E & E \\
\hline \multirow{4}{*}{$3 d$} & 5 & 15.50 & 1 & & & 50 & 13.73 & 1 & & \\
\hline & 10 & 10.18 & $1-2$ & & & 60 & 11.14 & $1-2$ & & \\
\hline & 20 & 5.57 & $2-3$ & & & 70 & 9.11 & $1-2$ & & \\
\hline & 80 & 1.92 & 4 & $\mathrm{E}$ & $\mathrm{E}$ & 80 & 5.29 & $2-3$ & $\mathrm{E}$ & E \\
\hline \multirow{4}{*}{$3 e$} & 5 & 18.12 & 1 & & & 50 & 24.21 & 1 & & \\
\hline & 10 & 10.35 & $1-2$ & & & 60 & 17.00 & 1 & & \\
\hline & 20 & 7.43 & 2 & & & 70 & 10.23 & $1-2$ & & \\
\hline & 80 & 1.44 & 4 & $\mathrm{E}$ & $\mathrm{E}$ & 80 & 3.93 & 3 & E & $\mathrm{E}$ \\
\hline
\end{tabular}

Data from both set of experiments were qualitative. It was determined that these dyes had a rating of $E$ which designated them as "very slow" with regard to their adsorption vs. time behavior on cellulose acetate (rate of dyeing test) [9a] and "poor" with regard to their temperature range properties [9b]. Poor temperature range properties indicate slow dyeing, as the equilibrium exhaustion for all dyes was much higher at lower temperatures.

\subsubsection{Quantitative Evaluation-Colour Difference Measurement}

Pairs of dyeings in different temperatures $(50,60,70,80$, $90^{\circ} \mathrm{C}$ ) for $1 \mathrm{~h}$ and pairs of dyeings for different dyeing times $(5,10,20,80,160 \mathrm{~min})$ at $85^{\circ} \mathrm{C}$ were measured spectrophotometrically and the colour differences $\Delta \mathrm{E}$ between pairs of samples described in the experimental part (Samples dyed at 90-50, 90-60, 90-70, 90-80 $\mathrm{C}$ ) for the evaluation of temperature range and pairs of samples dyed for $160-5,160-10,160-20,160-80 \mathrm{~min}$ for the evaluation of 
rate of dyeing were calculated (Tables 3,4,5). The grey scale values were given directly to the corresponding $\Delta \mathrm{E}$ value and the results of the two measurements (qualitative-quantitative) for each pair of samples were found to be in a very good agreement (Tables 3,4,5) i.e. the lowest $\Delta \mathrm{E}^{*}$ values were observed for the pairs dyed at $90-80^{\circ} \mathrm{C}$ and the pairs dyed for 160-80 min indicating "slow" or "very slow" dyes with respect to the rate of dyeing and "poor" with respect to the temperature range.

\section{References}

[1] Annen O, Egli R, Hasler R, Henzi B, Jacob H, Matzinger R. Replacement of disperse anthraquinonedyeS. Rev Prog Coloration, 17, 72-85 (1987).

[2] Stead C. V. Developments in azo colorants. Rev Prog Coloration, 1. 23-30 (1967).

[3] Hallas G. The effects of terminal groups in 4aminoazobenzeneand disperse dyes related thereto. J Soc Dyers Col, 95, 285-94 (1979).

[4] Griffiths J. Recent Developments in the Colour and Constitution of Organic Dyes. Rev Prog Coloration, 11, 3757 (1981).
[5] Tsatsaroni EG. Structure-Stability Relationships in some Azo-Disperse Dyes. Dyes and Pigments, 31, 301-07 (1996)

[6] Georgiadou K Tsatsaroni EG. Synthesis, characterization and application of some disperse dyes derived from N-2hydroxyethyl-1-naphthylamine. Dyes and Pigments, 50, $93-$ $97(2001)$

[7] Georgiadou K Tsatsaroni EG. Hetarylazo disperse dyes derived from substituted N,N-bis- $\beta$-hydroxy- and bis- $\beta$ acetoxy-ethylaniline. Dyes and Pigments, 53, 73-78 (2002)

[8] R. McDonald, Colour Physics for Industry, 2nd edition, Bradford, Society of Dyers and Colourists (1997).

[9] Report of the Committee on the Dyeing Properties of Disperse Dyes-Disperse Dyes on Secondary Cellulose Acetate, Proceedings of the Society, J. Soc. Dyers Col.,80, 237-42 (1964). 9a: Rate of Dyeing test; 9b:Temperature Range test.

[10] Griffiths J. Colour and constitution of organic molecules. Academic Press, London, 1976. p.181.

[11] Peters AT, Gbadamosi A. Disperse dyes: 4-hetarylazo derivatives from $\mathrm{N}-\beta$-cyanoethyl-N- $\beta$-hydroxyethylaniline. J Chem Tech Biotech 53, 301-8 (1992). 